\title{
What's happening next
}

\author{
Gaetano Rocco, MD, FRCSEd, ${ }^{\mathrm{a}}$ and Walter Weder, $\mathrm{MD}^{\mathrm{b}}$
}

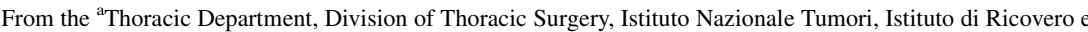
Cura a Carattere Scientifico, Fondazione Pascale, Naples, Italy; and ${ }^{\mathrm{b}}$ Department of Thoracic Surgery, University Hospital Zurich, Zurich, Switzerland.

Disclosures: Dr Rocco is a consultant for Scanlan International, St Paul, Minn. Dr Weder has nothing to disclose with regard to commercial support.

Received for publication Dec 5, 2017; accepted for publication Dec 14, 2017; available ahead of print Feb 1, 2018 Address for reprints: Gaetano Rocco, MD, FRCSEd, Thoracic Department, Division of Thoracic Surgery, Istituto

Nazionale Tumori, Istituto di Ricovero e Cura a Carattere Scientifico, Fondazione Pascale, Naples, Italy (E-mail: g.rocco@istitutotumori.na.it).

J Thorac Cardiovasc Surg 2018;155:1781-2

$0022-5223 / \$ 36.00$

Copyright (C) 2017 by The American Association for Thoracic Surgery

https://doi.org/10.1016/j.jtcvs.2017.12.060
}

In the last 20 years, the armamentarium of a modern thoracic surgeon has rapidly evolved with the incorporation of the principles of minimally invasive surgery, namely video-assisted thoracoscopic and robotic surgery. At the same time, our community has progressively escaped the ebony towers of our operating theaters to look toward the other specialists who concur in lung cancer management. As a result, our practice has changed; some changes have almost been imposed on us-as demonstrated by the growing role of stereotactic body radiotherapy for early-stage disease brought forward by the thriving and relentless efforts of radiation oncologists around the world-whereas some others were absorbed almost by osmosis from our colleagues the medical oncologists during the multidisciplinary sessions. An example of the latter is the exposure to the concept of targeted medical treatment originated by the evidence of a different drug susceptibility of lung cancer histotypes. ${ }^{1}$ Later, the results originating from innovative targeted therapy with biologic agents for a minority of patients with lung cancer with epidermal growth factor receptor mutations spurted a renewed enthusiasm destined to be curbed by the detection of drug resistance. ${ }^{2}$ Today, targeted therapy and immunotherapy represent new treatment regimens that are influencing our algorithms of care most rapidly and in an ever-evolving sequence. ${ }^{3}$

Whether it is right for the thoracic surgeons to learn these new dogmas by field experience or should a comprehensive syllabus including elements of thoracic oncology be added to the thoracic surgical curriculum is still a matter of debate. ${ }^{4}$ Be as it may, thoracic surgeons, as crucial members of multidisciplinary teams, cannot afford the luxury of ignoring the fundamental knowledge deriving from the basic research-generated druggable mutations or genetic pathways. Keeping abreast of the latest evolution of basic research and the attendant pharmacologic derivatives is not just a matter of cultural standstill but has rather become a matter of disservice to our patients.

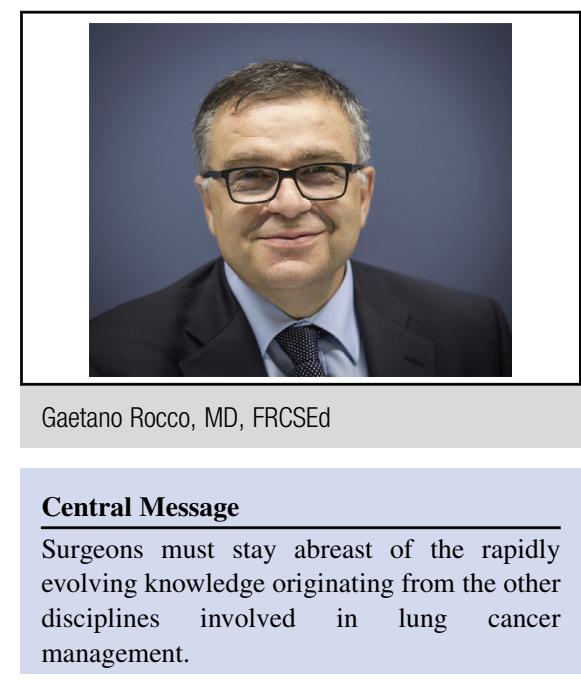

See Article page 1777.

In the commendable contribution by Rusch and colleagues ${ }^{5}$ from Memorial Sloan Kettering Cancer Center published in this issue of the Journal, this perspective is substantiated in as much as divulgation of knowledge is aimed at improving the surgeons' ability at interacting with their colleagues within MDTs to offer our patients the best possible standard of care. In fact, the use of checkpoint inhibitors is being studied both in an adjuvant setting as well as induction agents alone or in combination with more traditional treatment regimens. ${ }^{5}$ Long gone are times when only 1 drug was available for the comprehensive nonsmall cell lung cancer group-immunotherapy, with its multifaceted spectrum of efficacy and minimal side effects, promises to be at the center of innovative therapeutic regimens for the patients with advanced as well as earlydisease stages, either in a neoadjuvant or in an adjuvant setting. ${ }^{5}$ Another important contribution that surgeons may bring to the decision-making process for a multimodality treatment of lung cancer derives from the realization that the new and effective immunotherapeutic agents may be extremely expensive. Patients may not be in the necessary socioeconomic status to afford these medical regimens, thus incurring the so-called financial toxicity. ${ }^{6}$

In this ever-evolving multidisciplinary environment, the fate of our role as surgeons rests also on the way we approach our colleagues in MDTs. We need to shorten the distance kept in the past $^{7}$ while being ever in sight of the strongholds of our specialty and ready to shape our practice to adapt to the incumbent future. To understand the power of these new options and be actively involved in new studies 
on multimodality treatment, thoracic surgeons need to have a clear vision of what's happening next- the only way to know is to improve as surgeons by becoming a little more like scientists.

\section{References}

1. Scagliotti GV, Parikh P, von Pawel J, Biesma B, Vansteenkiste J, Manegold C, et al. Phase III study comparing cisplatin plus gemcitabine with cisplatin plus pemetrexed in chemotherapy-naive patients with advanced-stage non-small-cell lung cancer. J Clin Oncol. 2008;26:3543-51.

2. Soria JC, Ohe Y, Vansteenkiste J, Reungwetwattana T, Chewaskulyong B, Lee $\mathrm{KH}$, et al. Osimertinib in untreated EGFR-mutated advanced non-smallcell lung cancer. $N$ Engl J Med. November 18, 2017 [Epub ahead of print].
3. Reck M, Rodríguez-Abreu D, Robinson AG, Hui R, Csőszi T, Fülöp A, et al. Pembrolizumab versus chemotherapy for PD-L1-positive non-small-cell lung cancer. N Engl J Med. 2016;375:1823-33.

4. Massard G, Antonoff MB, Noel JL, Brunelli A, Farjah F, Lanuti M, et al. Transatlantic editorial: thoracic surgeons need recognition of competence in thoracic oncology. J Thorac Cardiovasc Surg. 2017;154: 1387-92.

5. Rusch VW, Chaft J, Hellmann M. KEYNOTE-024: unlocking a pathway to lung cancer cure? J Thorac Cardiovasc Surg. 2018;155:1777-80.

6. Perrone F, Jommi C, Di Maio M, Gimigliano A, Gridelli C, Pignata S, et al. The association of financial difficulties with clinical outcomes in cancer patients: secondary analysis of 16 academic prospective clinical trials conducted in Italy. Ann Oncol. 2016;27:2224-9.

7. Rocco G. Narcissus, the Beam, and lung cancer. J Thorac Cardiovasc Surg. 2016; 152:338-43. 